\title{
Underwater Image Enhancement and Object Detection using Edge Preserving and Multiscale Contextual Neural Network
}

\author{
Meenaakumari.M, Ramya.S,Balaji
}

\begin{abstract}
The submerged perception circumstances cause incredible difficulties to the issue of article location from the low-goals submerged pictures. In this paper, we acquaint an effective strategy with improve the pictures caught submerged and corrupted in light of the medium dispersing and retention. It expands on the mixing of 2 pictures that are legitimately gotten from a shading redressed and white-adjusted adaptation of the first corrupted picture. In the wake of improving the submerged picture, plans to identify object that present in the submerged by utilizing novel edge saving and multiscale logical neural network. We concentrated for the most part on discovery of an item in the submerged that they are utilized to isolate them an article from the foundation by utilizing a mix of programmed difference extending pursued by picture number-crunching task, worldwide edge, and least channel. Our system could be a solitary picture approach that doesn't need particular equipment or information about the submerged conditions or scene structure. our upgraded pictures are described by better exposedness of the dull area, improved worldwide complexity and edge sharpness and our striking article recognition accomplishes both clear identification limit and multi-scale logical vigor at the same time in this manner accomplishes an enhanced presentation.
\end{abstract}

Keywords: Underwater enhancement, Striking item revelation, edge safeguarding, multi-scale setting, RGB-D saliency identification, object cover.

\section{INTRODUCTION}

Submerged environment offers a few uncommon attractions like marine creatures and fishes, magnificent scene, and secretive wrecks. Other than submerged photography, submerged imaging has additionally been a significant supply of enthusiasm for various parts of innovation and research , like audit of submerged frameworks and links, identification of non-characteristic items, the board of submerged vehicles , sea life science investigation, and prehistoric studies [1-5].Technology progresses in kept an eye on and remotely worked submersibles enable individuals to gather pictures and recordings from a wide scope of the undersea world. Waterproof cameras have turned out to be well known, enabling individuals to effectively record submerged animals while swimming and plunging. These pictures or recordings

Revised Manuscript Received on August 22, 2019.

Meenaakumari.M Assistant Professor, Department of Electronics And Communication Engineering,, Bharath Institute of Higher Education and Research, Chennai, India.1meenumathi.m@gmail.com

Ramya.S, Assistant Professor, Department of Electronics And Communication Engineering,, Bharath Institute of Higher Education and Research, Chennai, India.2ramyasamdr@gmail.com

Balaji Assistant Professor, Department of Electronics And Communication Engineering,, Bharath Institute of Higher Education and Research, Chennai, India. bala.sripathy@gmail.com regularly experience the ill effects of shading contortion and low differentiation because of the proliferated light constriction with separation from the camera, basically coming about because of retention and dispersing impacts. Hence, it is attractive to build up a viable technique to reestablish shading and upgrade differentiate for these images.[6] Different from basic pictures, submerged pictures experience the ill effects of poor perceive ability following from the constriction of the engendered light, essentially because of assimilation and dissipating impacts. [7]

The assimilation impressively lessens the light vitality, while the dissipating causes changes inside the light-weight engendering bearing. They result in foggy look and refinement degradation, making far off articles cloudy. for all intents and purposes, in like manner sea water pictures, the articles at a separation of very ten meters are practically imperceptible, and furthermore the hues are blurred because of their forming wavelengths are sliced by the water profundity. [8]There are a few makes an endeavor to restore and upgrade the perceive ability of such debased pictures. Since the weakening of submerged scenes results from the blend of multiplicative and added substance forms customary improving procedures like gamma amendment, histogram balance appears to be intensely limited for such an undertaking. striking item location, which expect to distinguish object that most draws in individuals' consideration all through an image, has been wide misused lately. [9] this paper acquaints a totally extraordinary methodology with evacuate the cloudiness in submerged pictures dependent on one picture caught with a conventional camera.

As delineated in diagram 1, our methodology expands on the combination of various data sources, anyway infers the 2 contributions to blend by redressing the refinement and by honing a white-adjusted form of one local info picture.[10] The white evening out stage goes for expelling the shading strong prompted by submerged light dissipating, thusly as to give a characteristic look of the sub-ocean pictures. The multi-scale execution of the combination strategy prompts a curio free mixing it's additionally been wide utilized for a few PC vision errands, as semantic division object follow and picture characterization Conventional saliency ways expect to get a warmth map which gives each pixel an overall estimation of its dimension of saliency As of late, the design moves[10] 


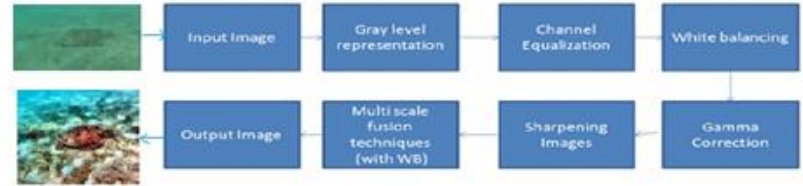

Fig.1 Enhancement Method overview

to remarkable article identification that produces pixel-wise parallel name for notable and non-notable items .

In examination with the glow map, the parallel mark would any benefit division basically based applications like semantics division [I], and in this way pulls in extra attention.To accomplish a high exactness for double naming, there ar in the primary 2 prerequisites: beginning, multi-scale talk dependability; and second, sharp limit among remarkable and non-striking articles. What's more, along these lines, the unmistakable limit intends to isolate the remarkable article and foundation obviously and to spotlight the absolute item consistently. tragically, none of the overarching systems achieve every need in the meantime. Customary base up procedures essentially think about priors or presumptions and carefully assembled highlights. for example, focus encompass contrast independence past and back roundness past [. These techniques can't consider abnormal state semantic talk relations and don't convey the merchandise a fantastic accuracy. Recently, the profound Convolutional Neural Network (CNN) has pulled in wide consideration for its prevalent exhibition. Convolutional Neural Network essentially based methodologies are regularly separated into locale-based systems and pixel-based systems. District based procedures expect to remove alternatives of each locale (or fix), so anticipate its striking ness score. In any case, existing district-based techniques absence of speaking to setting data to show the connection among locales and global scenes. In this paper, we propose a novel edge protecting and multi-scale logical system for remarkable item location. The proposed system accomplishes both clear limit and multi-scale relevant vigor all the while out of the blue. As showed in Fig. 2, the arranged structure, named Rex Net, is mainly created by 2 segments, the Region Net and along these lines the context Net. In the first place, the Region Net is inspired by the speedy R-Convolutional Neural Network system . fast R-Convolutional Neural Network is as of late gotten ready for article recognition and accomplishes unrivaled execution because of the convolutional alternatives of whole picture square measure shared and highlights of each fix (or RoI) square measure removed by means of the RoI pooling layer. we tend to stretch out fast R-Convolutional Neural Network to remarkable article recognition by presenting veil based RoI pooling and planning notable item discovery as a paired area characterization task. The picture is first separated into locales and square measure used as contribution of RegionNet, the Region Net at that point predicts noticeable quality score of each district start to finish to make conspicuousness guide of the total picture. Since the districts square measure partitioned by edge-saved ways, conspicuousness guide produced by our system is obviously with sharp limits.

Second, the Contex Net expects to give emphatically dependable multi-scale relevant information. entirely unexpected from previous works that are setted by elaborating district window at a precise layer, during this paper, we will in general consider demonstrating setting by means of numerous reflection scales. This is essentially founded on the perception that various layers of Convolutional Neural Network speak to various dimensions of phonetics, considering setting of different dimensions is likewise extra adequate. we will in general succeed this by taking advantages of thick picture forecast. For all maximum pooling layers of RegionNet, we will in general connect numerous convolutional layers to anticipate strikingness guide of different dimensions. At that point all dimensions of strikingness guide are solidified with Region Net to get a definitive strikingness map. Our procedure creates strikingness map with right area though keeping fine item limits. aside from the adequacy, our anticipated systems is efficient, since we will in general take advantages of locales by expanding the affordable speedy R-Convolutional Neural Network structure, that predicts strikingness score of areas by just 1 sending. we will in general conjointly stretch out our strategy to Red Green Blue-Depthstrikingness by applying profundity refinement. Investigations on two Red Green Blue-Depth benchmark datasets show that the anticipated RexNet beats elective ways by an outsized edge. the most commitments of this paper ar three-overlay. To start with, we tend to anticipateRegionNet that creates strikingness score of locales speedily and jelly object limits. Second, multi-scale deliberation setting is considered and snared to RegionNet to support notable article discovery execution. Third, we will in general stretch out our procedure to Red Green Blue-Depthstrikingness datasets and use profundity data to any refine saliency maps.

\section{II.RELATEDWORK}

In this area, we present customary notable discovery techniques and the ongoing Convolutional Neural Network based strategies. What's more, we present some related works that incorporate multiple-spectral setting data and identified with striking article identification

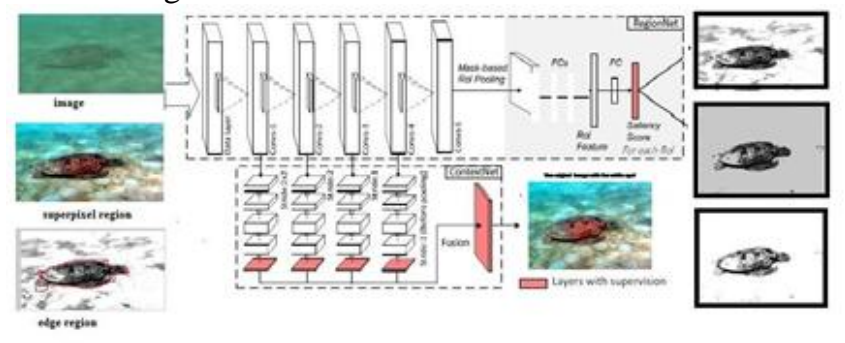

Fig. 2 Proposed Architecture

\section{A.TraditionalMethods}

Striking item discovery was first misused, and later pulled in consideration inside the PC antiquated methodologies generally concede earlier suspicions, and most are un-regulated. Focus encompass contrast that expect that remarkable locales varies from their nearby areas is an imperative past in early examination. Itti et al. first arranged focus encompass qualification at very surprising scales to register striking nature. Liu et al. propound focus encompass bar graph that characterizes striking nature because the distinction between focus locale and its nearby area suggested cost-touchy SVM to be told see striking districts that are entirely unexpected from their nearby areas. These systems can't

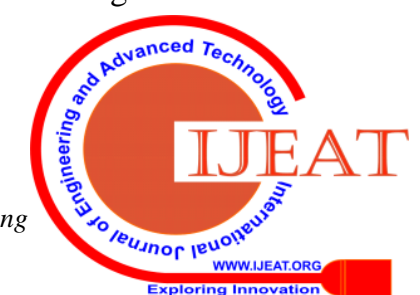


offer sharp limit for remarkable locale because of their upheld parallelogram districts, that is scarcely prepared to produce coarse and fluffy limit. [11-15]

Worldwide qualification based generally ways . In picture is separated into super pixels. At that point striking nature cost of each area is laid out in light of the fact that the refinement with every elective district. The qualification is weighted by reflection separate with the goal that nearby areas have greater effect on it. To fight with articles with convoluted propose a stratified model that investigates notability signals from various scales bolstered nearby complexity thus construes a definitive remarkable quality estimation of locales by improving them in a very tree model. Tailing them, a few different ways using base up priors square measure anticipated, peruses are urged to search out a ton of subtleties in an extremely late review.

\section{B.Convolutional Neural Network Technique}

Profound $\mathrm{CNN}$ has pulled in a ton of consideration for its remarkable execution in the abnormal state etymology. Here, we tend to specify are not many agentsworks. These works will be isolated into 2 classes in venture with their treatment of information pictures: area-based systems and pixel-based procedures. Area based procedures plan notable item location as a section arrangement task, to be specific, separate in choices of locales and anticipate their striking ness score. though pixel-based systems straightforwardly anticipate striking ness map with picture elements in Convolutional Neural Network.

Region-Based Methods: put forward to discover remarkable article by integration every local estimation and world hunt with 2 prepared systems DNN-L and DNN-G. suggested a world and normal setting by swing a worldwide and a closer-engaged super pixel-focused window to remove alternatives of each super pixel, severally, thus blend them to foresee unmistakable quality score. $\mathrm{Li}$ et al. recommended a multi-scale profound alternative by separating choices district with 3 scales thus combine them to get its noticeable quality score. These works territory unit locale put together that focused with respect to removing alternatives of districts and wire bigger size of areas as setting to anticipate unmistakable quality score of each locale. This combination is normally connected at just 1 layer and doesn't get through an ideal execution. moreover, the systems remove alternatives of 1 area for each sending that is very long.

Picture element Techniques: Convolutional Neural Network has been connected with picture element thick picture expectation, similar to phonetics division and striking nature forecast. Long et al. propose completely a convolutional arrange that is prepared start to finish and pixels-to-pixels by presenting completely convolutional layers and a skip plan suggested a coarse-to-fine way inside which the essential convolutional neural network produces coarse guide exploitation the total picture as information thus the second convolutional neural network takes the coarse and nearby fix as contribution to think of fine-grained notability map. Li et al. propose a perform various tasks model upheld convolutional organize.
Red Green Blue -Depth Detection Red Green Blue-Depth algorithm is a developing point and most Red Green Blue-Depth prominence techniques depend on melding profundity along with Red Green Blue prominence. suggest Red Green Blue-Depth prominence strategy dependent on anisotropic focus encompass distinction, in which prominence is estimated as the amount surroundings. propound profundity notability with multi-talk qualification so meld it with look prompts through a multi-arrange model. Ren et al. recommended standardized profundity past and worldwide setting surface direction past upheld profundity information so meld them with Red Green Blue district qualification priors. Profundity refinement could prompt false encouraging points in foundation area, to deal with [ profound local foundation fenced in area highlight upheld the perception that striking articles will in general be locally in front of close areas. The least difficult of our information, existing Red Green Blue-Depth notable item recognition square measure all abuse hand-lingered choices and furthermore the presentation isn't enhanced.[16-20]

\section{C.Multiple-Spectral}

Multiple-spectral setting are demonstrated with a valuable of picture division to be done . Hariharan et al. proposed hyper columns for article division and fine-grained restriction, in which they characterized "hyper column" at a given info area as the yields of all layers at that area. Highlights of various layers are consolidated and after that be utilized for grouping. Zhao et al. proposed multi-setting system which concentrates highlights of a given super pixel at worldwide and neighborhood scale, and afterward anticipate saliency estimation of that super pixel. $\mathrm{Li}$ et al. proposed to concentrate highlights at three scales: bouncing box, neighborhood rectangular and the whole picture. Liu et al. Jproposed to utilize intermittent convolutional layers (RCLs) iteratively to coordinate setting data and to refine saliency maps. At each progression, the RCL takes coarse saliency map from last advance and highlight map at lower layer as contribution to foresee a better saliency map.

\section{D.Obsession Forecast and Image Reduction}

Obsession expectation, plans to anticipate the districts individuals may focus on, and semantic segmentation, intends to section objects of specific classes in pictures. They are subjects identified with striking item location, yet they likewise have critical contrasts. Obsession expectation plans to anticipate areas which most pull in individuals' consideration, while striking item location centers around portioning the most attractive articles. For semantic division, saliency discovery is a class-rationalist undertaking, regardless of whether an article is remarkable or not is generally rely upon its environment, while semantic segmentation essentially centers around division objects of specific classes. So contrasted and semantic division, setting data is increasingly significant for saliency location, and this is the fundamental inspiration of the Context Net.

\section{PROPOSEDALgORITHM}

Info picture may under the configuration of jpg or bmp, Various kinds of organizations, for example, 
gif, tif, png and so on., Input picture ought to be in the arrangement of RGB. In dim dimension obstruct the information picture is given in the RGB group and the picture is changed over to Gray scale G.for the handling speed.

\section{E .Enhancement Process}

Our picture upgrade approach fig 1adopts a two-stage methodology, joining white adjusting and picture combination, to improve submerged pictures without depending on the unequivocal reversal. In our methodology, white adjusting goes for making up for the shading cast brought about by the ingestion of hues with profundity, while picture combination is included to improve the corner and subtleties, to alleviate the differentiation coming about because of back-dispersing. We currently center around the white-adjusting stage. White-adjusting goes for improving the picture viewpoint, fundamentally by expelling the undesired shading castings because of different brightening or medium lessening properties. we based combination standards a solitary picture submerged arrangement. Picture combination has appeared in a few applications, for example, picture compositing, multispectral video upgrade defogging and HDR imaging, fig 1 depicts Input picture may under the organization of jpg or bmp, Various kinds of configurations, for example, gif, tif, png and so forth., Input picture ought to be in the arrangement of RGB. In dark dimension obstruct the information picture is given in the RGB group and the picture is changed over to Gray scale for the handling speed. The language structure utilized for the portrayal is rgb2gray ('input image, 'format"). This portrayal introduces

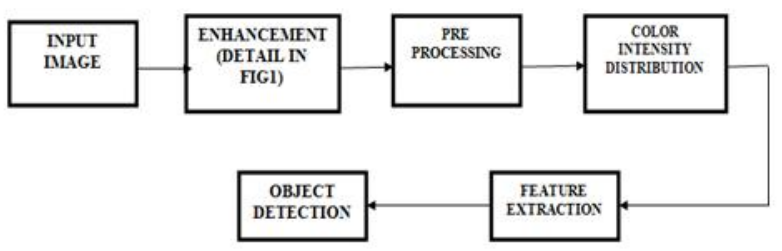

\section{Fig.3 Block diagram for proposed method}

the first picture record group. Techniques to perform show gamma redress in figuring. The pixel's power esteems in a given picture record. The paired pixel esteems are put away in the document in such way that they speak to the light power by means of gamma-compacted values rather than a straight encoding. Sharpening a picture expands the differentiation among splendid and dull locales to bring out features. The honing procedure is fundamentally the use of a high pass channel to an image. We investigate a strategy for multiscale deterioration on a picture using high and low pass channels, creating subtleties and approximations respectively. Here, the low pass channel is an ordinary circulation and the high pass channel is a DoG: Derivative-of-Gaussian

\section{F .Pre-preparing}

Play out the characterization by pre-preparing the pictures utilizing Otsu's thresholding. With the execution of Otsu's thresholding, a dark dimension histogram is made from the dim scale picture for clamor evacuation, if a pixel of the grayscale is more prominent than the limit esteem, it is viewed as white, else pronounced as dark. The picture furnishes a beyond any doubt frontal area with the item in core interest.

\section{G. Color force circulation}

Shading force circulation is finished by direct differentiation extending. One of the least complex piece shrewd straight capacities is a differentiation extending change. It endeavors to improve a picture by extending the scope of power esteems it contains to make brimming with potential qualities. Low differentiation picture can result from poor end, absence of dynamic ranges from preprocessing output. Adjust the picture power esteems with a straight complexity extending.

\section{H. Feature extraction}

In picture process, during which calculations are utilized to watch and confine various wanted segments or shapes (highlight) of a digitized picture or video stream. it's quite significant inside the space of optical character acknowledgment. The regular strategies for picture highlight the process of removing will be separated as 3 classifications: point include the process of removing, straight element the process of removing and district highlight extraction The locale is the pixels set which have a dim scaling relationship in picture, where pixels have comparable functional elements, for instance the dim esteem, surface, etc. In any case, picture highlight descent calculation is additionally separated into highlight descent calculation dependent on edges with highlight descent calculation dependent on invariant innovation. Picture point highlight is the extraordinary element of the critical point in the picture. Edge is a widely recognized component point. It has been broadly connected to $\mathrm{PC}$ view. Above all, quantity of edges is significantly lesser than the quantity of all pixels in the picture, address issue of concentrate highlight focuses. Edge location calculation at present can be outlined into three classifications: dark dimension corner identification, parallel corner recognition and corner discovery through ebb and flow scale space For instance, CSS corner location technique is a corner identification strategy-based profile bend. The principle thought of Speeded Up Robust Feature calculation is ascertaining grid, searching the neighborhood maxima to find situation of the element segment, that is near the Scale Invariant Feature Transform calculation as far as light change, yet as far as fluffy invariance, rotational invariance and heartiness surpass Scale Invariant Feature Transform calculation, and which is multiple numbers quicker in count speed than Scale Invariant Feature Transform calculation, as a progressively amazing element extraction calculation

\section{I.Objec detection}

The item limitation is acquired because of programmed edge protecting, histogram evening out and picture math.

STEP 1: Adjust the element separated picture power esteems with an edge saving. (L)

STEP2: Perform the Histogram balance as $(\mathrm{H})$ 
Stage 3: Brighten most of the subtleties, Obtain the picture $\mathrm{R} 1=\mathrm{L}+\mathrm{H}$

STEP 4: Highlight all the item and its fringes in the picture. Get the picture R2=L-H.

STEP5: Remove practically the various segments. Acquire the picture $\mathrm{R} 3=\mathrm{R} 1+\mathrm{R} 2$.

Stage 6: Implement, multiple times, 3-by-3 least channel on the picture R3.

STEP7: Convert R3 to paired picture utilizing the edge from stage 6.

Stage 8: Acquire the outcome

Message Data

Message Data

MessageData

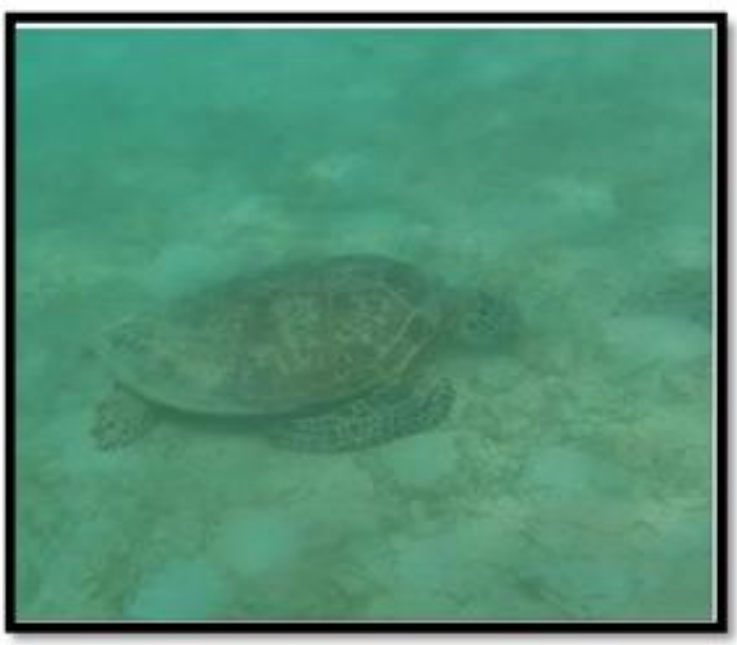

Fig.1Message Data

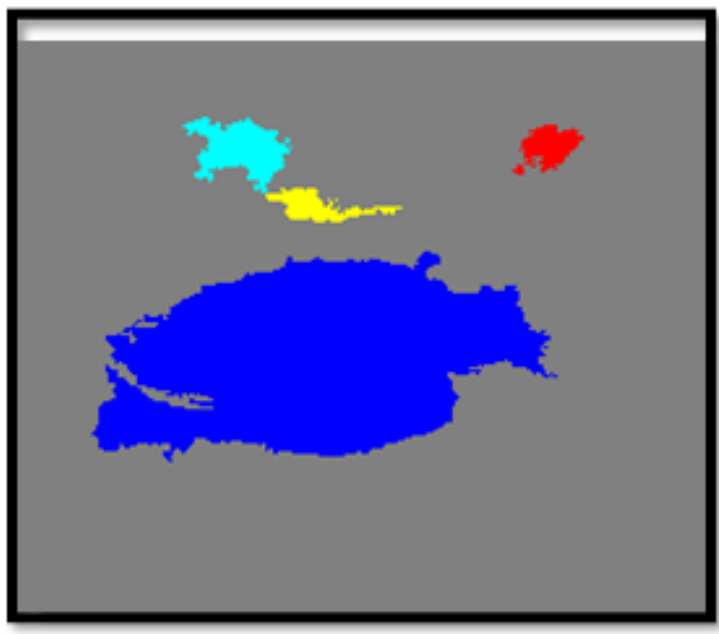

Fig.2Color intensity distributed image

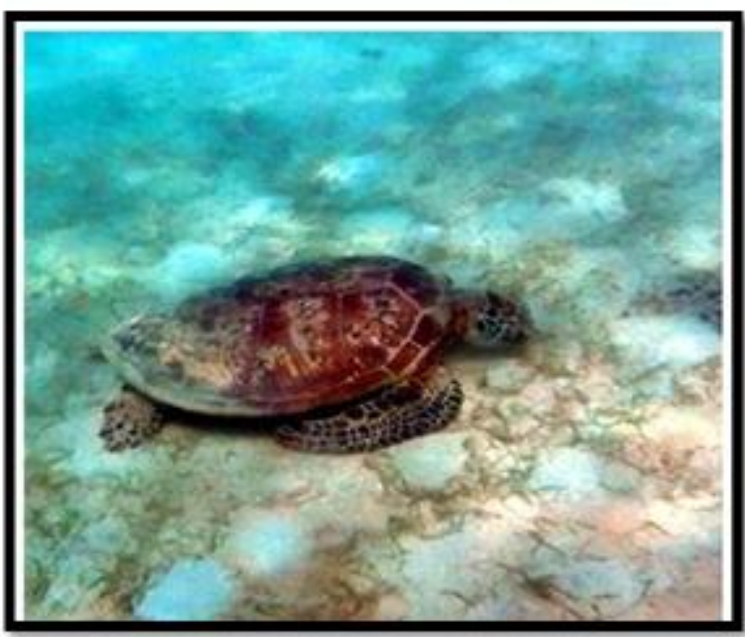

Fig.3Enhancement of data

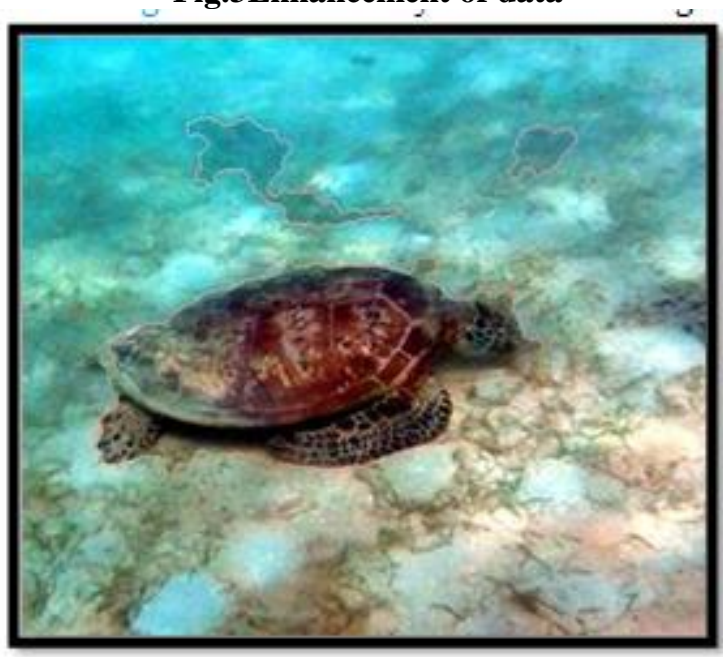

Fig.4Feature extracted image

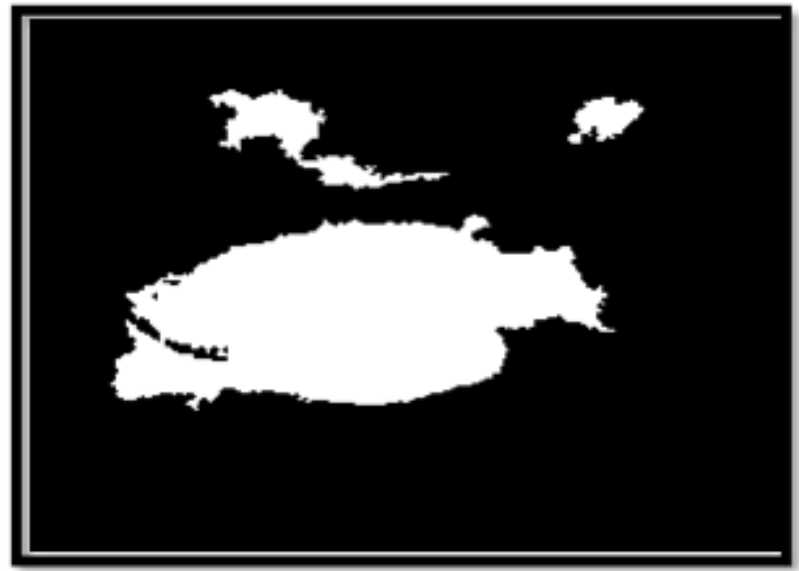

Fig.5Preprocessed Image

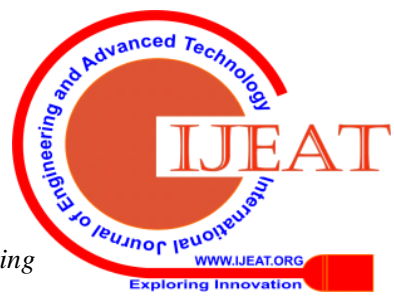




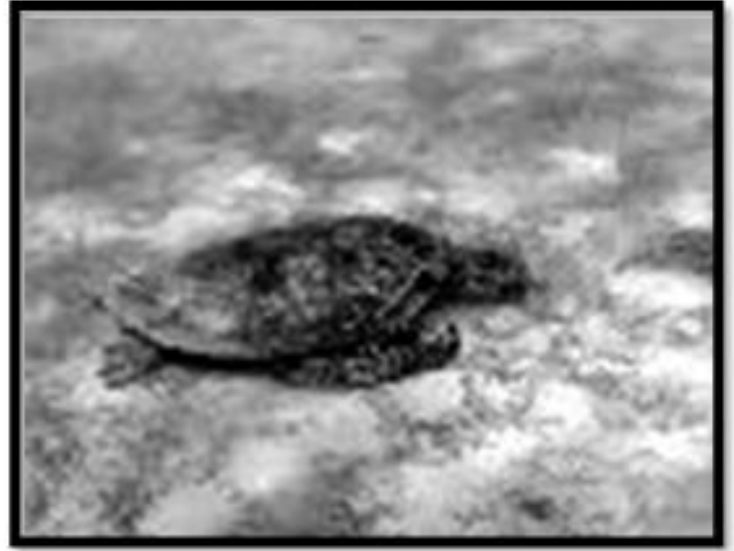

Fig.7Brighten most of the Details

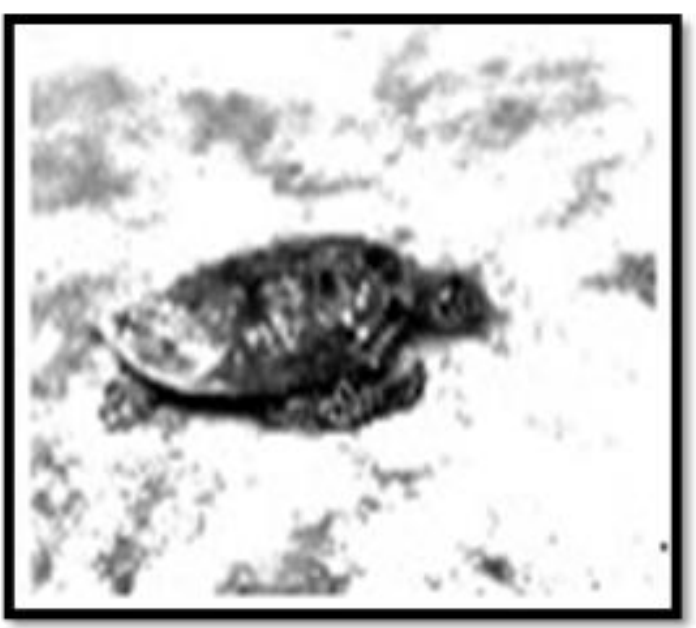

Fig.9Highlights all the object in the image

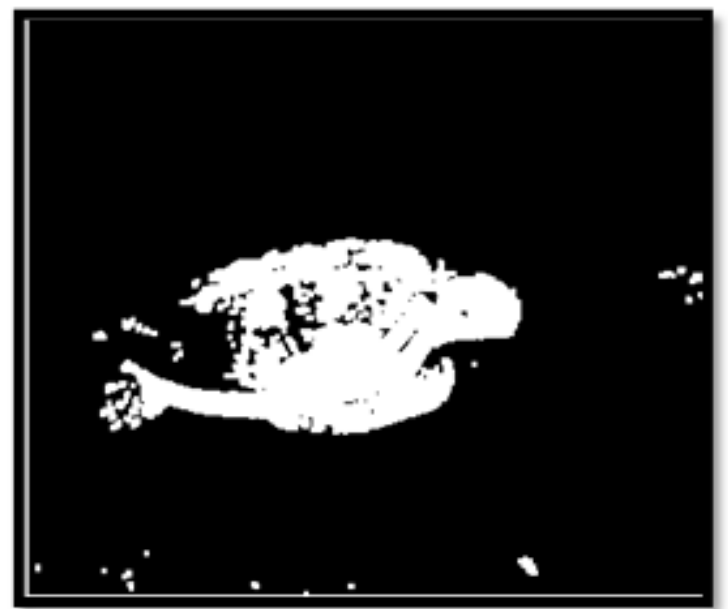

Fig.6Global thresholding

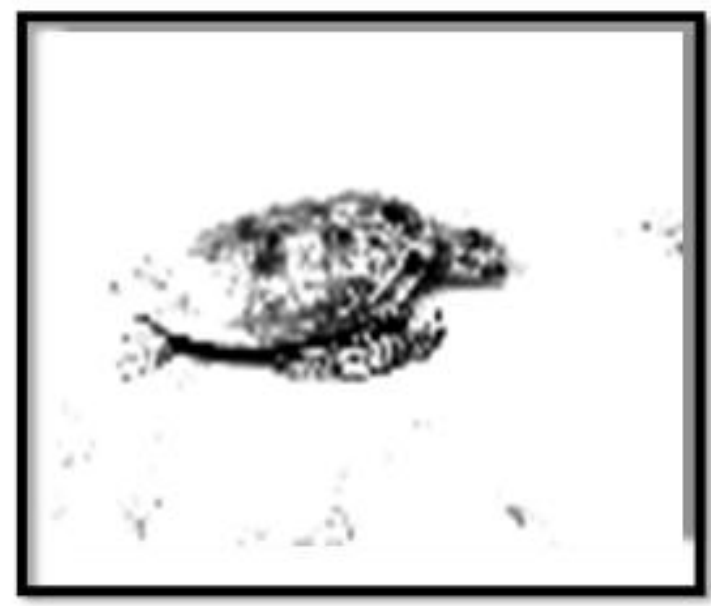

Fig.8 Remove all other components

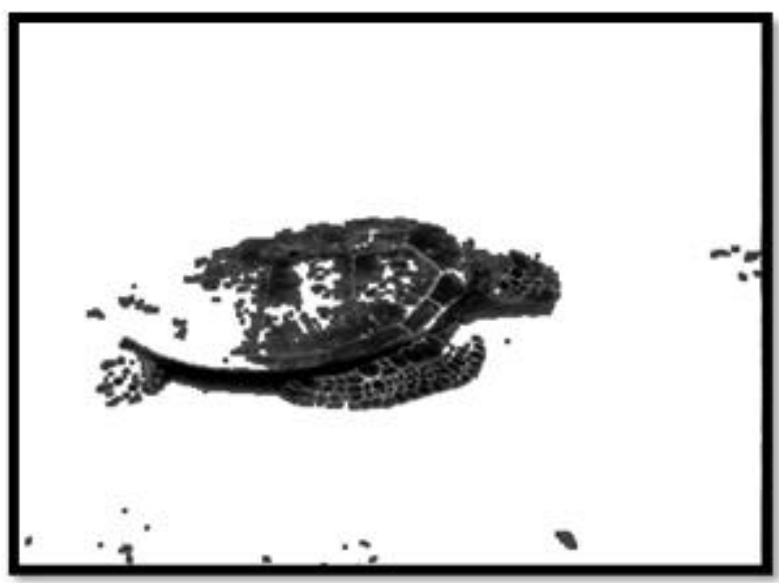

Fig.10Final detected image

\section{IV.CONCLUSION}

In this paper we proposed an elective way to deal with upgrade submerged pictures. Our methodology expands on the combination standard and does not require extra data than the single unique picture. We have appeared in our examinations that our methodology can improve a wide scope of submerged pictures with high exactness, having the option to recuperate significant blurred highlights and edges and our striking article recognition by utilizing novel edge protecting and multiscale relevant neural system accomplishes clear discovery limit and multi-scale logical vigor at the same time along these lines accomplishes an advanced presentation. we concentrated primarily on discovery of an article in the submerged that they are utilized to isolate them an item from the foundation by utilizing a blend of programmed difference extending pursued by picture number juggling activity, worldwide limit, and least filter. Thus, created better after effect of submerged notable article recognition.

\section{REFERENCES}

1. Kongkham, D. \& Sundararajan, M. 2019, "Distributed wideband sensing method for faded dynamic spectrum access", International Journal of Innovative Technology and Exploring Engineering, vol. 8, no. 10, pp. 4309-4312.

2. Balaji, S., John Paul Praveen, A. \& Mohanraj, R. 2019, "Recognizable proof and analysis of palm print in biometric

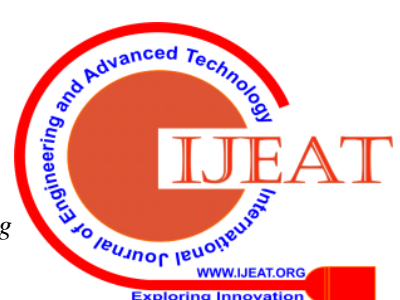


authentication system using bayes techniques", International Journal of Innovative Technology and Exploring Engineering, vol. 8, no. 9 Special Issue 3, pp. 1126-1129.

3. Kavitha, G., Priya, N., Velvizhi, R. \& Allin Geo, A.V. 2019, "Parallel computation in correspondence and signal processing", International Journal of Innovative Technology and Exploring Engineering, vol. 8, no. 9 Special Issue 3, pp. 1136-1139.

4. Hema, R., Sundararajan, M. \& Balaji, S. 2019, "Smartphone control robot with automatic firing gun", International Journal of Innovative Technology and Exploring Engineering, vol. 8, no. 9 Special Issue 3, pp. 625-627.

5. Kaliyamurthie, K.P., Sundar Raj, B., Velvizhi, R. \& Shanmugapriya, K. 2019, "Dual band paper substrate CPW antenna for wireless applications", International Journal of Innovative Technology and Exploring Engineering, vol. 8, no. 9 Special Issue 3, pp. 605-608.

6. Geo, A.V.A., Arunachalam, A.R., Michael, G. \& Elankavi, R. 2019, "Evaluating architecture using compact modalities", International Journal of Innovative Technology and Exploring Engineering, vol. 8, no. 9 Special Issue 3, pp. 836-838.

7. Theivasigamani, S., Jeyapriya, D. \& Anita Davamani, K. 2019 , "Anamoly analyzing and exploring for wireless sensor networks", International Journal of Innovative Technology and Exploring Engineering, vol. 8, no. 9 Special Issue 3, pp. 1116-1118.

8. Jeyapriya, D., Theivasigamani, S., Velvizhi, R. \& Nandhini, P. 2019, "Program detection in wireless feeler networks", International Journal of Innovative Technology and Exploring Engineering, vol. 8, no. 9 Special Issue 3, pp. 1194-1195.

9. Gowri Sankaran, B., Karthik, B. \& Vijayaragavan, S.P. 2019, "Image compression utilizing wavelet transform", International Journal of Innovative Technology and Exploring Engineering, vol. 8, no. 10, pp. 4305-4308.

10. Gowri Sankaran, B., Karthik, B. \& Vijayaragavan, S.P. 2019, "Weight ward change region plummeting change for square based image huffman coding", International Journal of Innovative Technology and Exploring Engineering, vol. 8, no. 10, pp. 4313-4316.

11. Hema, R., Sundararajan, M. \& Balaji, S. 2019, "Smartphone control robot with automatic firing gun", International Journal of Innovative Technology and Exploring Engineering, vol. 8, no. 9 Special Issue 3, pp. 625-627.

12. Rangaswamy, K. \& Rajabhushanam, C. 2019, "Congestion control in wireless network using TCP friendly rate control (TFRC)", International Journal of Recent Technology and Engineering, vol. 8, no. 2 Special issue 3, pp. 1598-1602.

13. Tamil Selvan, S. \& Sundararajan, M. 2019, "Performance Parameters of 3 Value 8t Cntfet Based Sram Cell Design Using H-Spice", International Journal of Recent Technology and Engineering, vol. 8, no. 2 Special issue 5, pp. 22-27.

14. Vinoth, V.V. \& Kanniga, E. 2019, "Steganographical techniques in hiding text images - system", International Journal of Recent Technology and Engineering, vol. 8, no. 2, pp. 6535-6537.

15. Saravana, S., Balaji, S., Arulselvi, S. \& John Paul Praveen, A. 2019 "Reliable power quality monitoring and protection system", International Journal of Innovative Technology and Exploring Engineering, vol. 8, no. 9 Special Issue 3, pp. 644-645.

16. Sundaramoorthy, A. \& John Wiselin, M.C. 2019, "Single patch antenna with multiple feed", International Journal of Innovative Technology and Exploring Engineering, vol. 8, no. 9, pp. 1743-1747.

17. Velavan, R., Bharanidharan, S. \& Sheeba, B. 2019, "EMF pollution Causes, effects and protection", International Journal of Innovative Technology and Exploring Engineering, vol. 8, no. 9 Special Issue 3, pp. 1166-1168.

18. Veer, R.A., Arulselvi, S. \& Karthik, B. 2019, "Construction of ensemble square classification approaches in MIMO OFDM", International Journal of Engineering and Advanced Technology, vol. 8, no. 5, pp. 2039-2041.

19. Agitha, W. \& Kaliyamurthie, K.P. 2019, "Improved energy efficient in WBAN using MAC with cloud computing", International Journal of Innovative Technology and Exploring Engineering, vol. 8, no. 8, pp. 2405-2408.

20. Kastro, G.G. \& Wiselin, M.C.J. 2019, "Design and analysis of stub loaded resonator", International Journal of Recent Technology and Engineering, vol. 8, no. 1 Special Issue4, pp. 272-283.

\section{AUTHORS PROFILE}

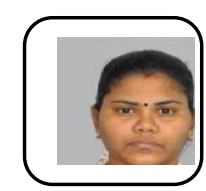

Meenaakumari.M Assistant Professor, Department of Electronics And Communication Engineering, Bharath Institute of Higher Education and Research, Chennai, India.

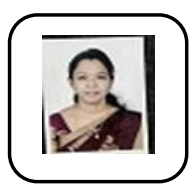

Ramya.S, Assistant Professor, Department of Electronics And Communication Engineering,, Bharath Institute of Higher Education and Research, Chennai, India..

Balaji Assistant Professor, Department of Electronics And Communication Engineering, Bharath Institute of Higher Education and Research, Chennai, India. 